\title{
Assessment of temperature susceptibility for rubber granulate modified road asphalt binders considering impact of aging
}

\author{
Mieczysław Słowik ${ }^{1 *}$, Damian Wiśniewski ${ }^{2}$, Marcin Bilski $^{1}$, Marta Mielczarek ${ }^{1}$ \\ ${ }^{1}$ Poznan University of Technology, Faculty of Civil and Environmental Engineering, Institute of Civil \\ Engineering, Piotrowo 5, 61-138 Poznań, Poland \\ ${ }^{2}$ UTP University of Science and Technology in Bydgoszcz, Faculty of Building, Architecture and \\ Environmental Engineering, Al. Prof. S. Kaliskiego 7, 85-796 Bydgoszcz, Poland
}

\begin{abstract}
The article presents the results of research on temperature sensitivity of ground rubber modified asphalt binders. The tests were performed for 50/70 penetration grade road bitumen and two kinds of granulated rubber: activated and inactivated. Such parameters of asphalt binders as: penetration, softening point, dynamic shear modulus and phase angle have been determined and on this basis the temperature susceptibility of the reference bitumen and asphalt binders modified by activated and inactivated rubber have been determined. All the tests were carried out for three observation levels: without aging and after aging simulations carried out by RTFOT and PAV methods. The tests revealed that addition of granulated rubber has a positive influence on asphalt binder properties, even after the aging process, causing an increase in the softening point and a decrease in penetration and the phase angle of asphalt binder. Asphalt binders obtained in result of modification by addition of rubber show smaller temperature susceptibility than the reference bitumen (without addition of rubber). Also, a positive impact of aging on the temperature susceptibility was observed for the investigated binders.
\end{abstract}

\section{Introduction}

Nowadays, more and more attention is being paid to ecological solutions (protecting the environment). It also applies to road engineering whose research centers search for new materials and trying to identify development directions for material-technological solutions which take into account the rules of sustainable development [1]. One of additives used for production of asphalt mixtures is crumb rubber recovered from used car tires. Rubber scrap is very harmful to the natural environment due to its very long degradation period, reaching even more than 100 years. Therefore, its reusing is a very good utilization method, especially that, due to the development of motorization industry, the number of tires is constantly increasing and subsequently, rubber scrap needs to be managed in an ecological manner. Thus, the issues raised in our article fit into the subject of sustainable development.

\footnotetext{
*Corresponding author: mieczyslaw.slowik@put.poznan.pl
} 
One of the materials most commonly used in road pavements is bitumen which blended with aggregate and filler at high temperature makes up a Hot Mix Asphalt (HMA). It is supposed to bind all the components of asphalt mixture. Bitumen belongs to thermorheological materials. In result of heating, bitumen gradually changes from solid to liquid state which leads to viscosity reduction. However, when cooled, it changes from liquid to solid state which is accompanied by an increase in its viscosity and stiffness modulus. The type of asphalt binder and its properties have a large influence on properties of the asphalt mixture which, subsequently affects performance of the road pavement.

The properties of road bitumen depend on temperature and time of loading. Therefore, it is necessary to increase the viscoelastic range of asphalt binder to maintain its rheological state, despite extremal temperatures reached by the pavement during service. A wide range of viscoelasticity can be obtained through the bitumen modification which involves adding appropriate amounts of modifying agents which include: fibers (polyester, polypropylene, mineral wool, cellulose), sulfur, natural asphalts (e.g.. Trynidad Epuré, Gilsonite), fillers, organometallic compounds, polymers, or synthetic wax.

By using modifying additives in asphalt binder it is possible to obtain the following effects: decreasing temperature susceptibility $[1 \div 8]$, increasing viscosity $[6,9]$, increasing dynamic shear modulus at high temperatures and its decreasing at low temperatures $[2,4,5,8]$, reduction of Fraass breaking point [7], raising the softening point $[6,8,9]$, penetration value change $[6,9]$.

Used tire rubber is considered to be an asphalt binder modifier. The obtained ground rubber can be added directly to bitumen (wet 'modification') or to asphalt mixture, through replacement of a part of fraction of aggregate ('dry' modification). Rubber crump addition by the 'wet' method or the 'dry' one has a positive influence on different properties of asphalt binder as well as asphalt mixture, which is confirmed by a great number of tests $[4,5,6,7,8,9,10,11,12,13,14]$. The influence depends on the degree of fineness and the amount of used granulated rubber which affect the bitumen viscosity, its rheological properties, softening point change, the binder penetration and values of dynamic shear modulus $[15,16,17,18]$.

\section{Research subject}

The aim of the study was to assess the influence of road bitumen selected properties, especially on its temperature susceptibility and resistance to aging. 50/70 penetration grade bitumen, commonly applied in asphalt pavements, was used for the tests. The tests were performed for three kinds of binder: reference bitumen 50/70 (with no addition of rubber), asphalt binder $50 / 70$ with addition of $15 \%(\mathrm{~m} / \mathrm{m})$ activated rubber and asphalt binder $50 / 70$ with addition of $15 \%(\mathrm{~m} / \mathrm{m})$ of inactivated rubber.

The process of activation was performed with the use of a production line consisting of the following elements: electromagnetic mill with a generator of microwaves, centrifugal rotor turning with the supersonic speed and other auxiliary equipment. The ground car tire rubber was successively processed, initially by means of mechanical- chemical activation, next it was subjected to synthesis and nano-synthesis. It allowed to obtain a new material whose structure is very similar to polymer structure [19].

All binders were tested for their rheological and functional properties at three observation levels: unaged, subjected to short term aging and then long term aging. On the basis of the carried out tests assessment of temperature susceptibility was performed for unmodified bitumen and crump rubber modified asphalt binders. 


\section{Asphalt binders research methodology}

\subsection{Determination of bitumen penetration and softening point}

Penetration and softening temperature belong to the basic properties of asphalt binders. Penetration is the measure of consistency (stiffness) of the binder. Softening point value defines the conventional, upper boundary of the viscoelastic state.

Determination of penetration with the use of a needle is performed according to the standard PN-EN 1426:2015-08 Bitumen and bituminous binders. Determination of needle penetration. The test involves determination of depth (in $0.1 \mathrm{~mm}$ ), a penetration needle with mass $100 \mathrm{~g}$ enters a specimen of bitumen in time of $5 \mathrm{~s}$ at $25^{\circ} \mathrm{C}$.

Determination of softening point is carried out according to Ring and Ball method described in the standard PN-EN 1427:2015-08 Bitumen and bituminous binders Determination of the softening point - Ring and ball method.

\subsection{Determination of rheological properties of asphalt binders by Dynamic Shear Rheometer (DSR) method}

The test in a rheometer DSR is carried out in order to define complex rheological properties of asphalt binders - viscoelastic materials. The test involves determination of complex shear modulus $\mathrm{G}^{*}$ and phase angle $\delta$.

Value $G^{*}$ is expressed as a ratio of maximal value of shear stress to the maximal value of strain. Value $\delta$ is a difference of phases between strain and stress in case of harmonic vibrations occurrence. When $\delta=90^{\circ}$, then asphalt binder can be considered an ideally viscous liquid, whereas when $\delta=0^{\circ}$, the material is found to be an ideally elastic body [20]. It is assumed that between these two boundary values, asphalt binder exhibits viscoelastic properties. The above values can be defined in the following way:

$$
\left|G^{*}\right|=\sqrt{G^{\prime 2}+G^{\prime 2}}
$$

or as a complex number:

$$
G^{*}=G^{\prime}+i G^{\prime \prime}
$$

and

$$
\delta=\operatorname{tg}^{-1}\left(\frac{G^{\prime \prime}}{G^{\prime}}\right)
$$

where:

$$
\begin{aligned}
& G^{\prime}=\left|G^{*}\right| \cos \delta \text { - is a storage modulus, which defines the material ability to } \\
& \text { store energy (real part of complex shear modulus); } \\
& G^{\prime \prime}=\left|G^{*}\right| \sin \delta-\text { is a loss modulus which defines the material ability to } \\
& \text { dissipate energy (imaginary part of complex shear modulus); } \\
& \operatorname{tg} \delta=\frac{G^{\prime \prime}}{G^{\prime}} \text { is a damping factor; } \\
& \mathrm{i}-\text { is an imaginary unit described by the equation } i^{2}=-1 \text {; } \\
& \left|G^{*}\right| \text { - dynamic shear modulus; } \\
& G^{*} \text { - complex shear modulus } \\
& \delta \text {-phase angle. }
\end{aligned}
$$


The test in Dynamic Shear Rheometer was carried out according to the standard PN-EN 14770:2012 Bitumen and bituminous binders - Determination of complex shear modulus and phase angle using a Dynamic Shear Rheometer (DSR). The test procedure involved placing an asphalt binder specimen with mass of $0.100 \div 0.105 \mathrm{~g}$ on a measurement head (plate) with diameter of $8 \mathrm{~mm}$., which was thermostated for $10 \mathrm{~min}$. in the temperature of testing. After thermostating process a measurement was started, for constant angular frequency equal to $10 \mathrm{rad} / \mathrm{s}$ and in a fixed temperature, starting with $82^{\circ} \mathrm{C}$, and next gradually (every $1^{\circ} \mathrm{C}$ ) down to $0^{\circ} \mathrm{C}$.

\subsection{Test of asphalt binder resistance to aging}

The asphalt binders were also subjected to aging: short term aging simulated in accordance with the standard PN-EN 12607-1:2014-12 Bitumen and bituminous binders. Determination of the resistance to hardening under influence of heat and air. RTFOT method, and next long term aging simulated according to the standard PN-EN 14769:2012 Bitumen and bituminous binders - Accelerated long-term ageing conditioning by a Pressure Ageing Vessel (PAV).

RTFOT (Rolling Thin Film Over Test) method involves putting a thin film of an asphalt binder under the impact of heated air at a period of time equal $75 \pm 1$ min. Bitumen specimen is poured to glass bottles which are successively placed in a turning disc turning with the speed $15,0 \pm 0,2 \mathrm{rpm}$, placed in a laboratory oven and exposed to temperature $163^{\circ} \mathrm{C} \pm 1^{\circ} \mathrm{C}$ and compressed air with flow rate 4,0 1/min $\pm 0,2 \mathrm{l} / \mathrm{min}$ and maximum pressure $200 \mathrm{kPa}$. RTFOT method simulates changes within the structure and properties of asphalt binder occurring during technological processes of asphalt mixture production and paving (mixing the aggregate with bitumen, transport of asphalt mixture, paving and compacting of the asphalt layer).

PAV (Pressure Aging Vessel) method involves exposing a specimen of the binder to the impact of air under pressure $2.1 \mathrm{MPa} \pm 0.1 \mathrm{MPa}$ in time of $20 \mathrm{~h}$ at $90^{\circ} \mathrm{C}, 100^{\circ} \mathrm{C}$ or $110^{\circ} \mathrm{C}$, sustained with tolerance of $\pm 0,2^{\circ} \mathrm{C}$. The asphalt binder tested by this method must first be subjected to aging by RTFOT. In the tests performed as part of this study the binder resistance to aging was assessed by means of PAV method in temperature $100 \pm 0,2^{\circ} \mathrm{C}$. PAV method simulates changes that occur in the asphalt binder during long term operation of the asphalt pavement (app. 10. years).

\subsection{Determination of values characteristic of asphalt binder temperature susceptibility}

Temperature susceptibility of a binder is commonly defined by means of penetration index which is determined on the basis of the asphalt binder softening point and penetration. Penetration index specifies how the asphalt binder changes its consistency (stiffness) in relation to temperature changes. The higher value of the penetration index the lower asphalt susceptibility to temperature changes. Penetration index (PI) is determined using the following formula [21]:

$$
P I=\frac{1952-500 \log \left(\text { Pen }_{25}\right)-20 T_{P i K}}{50 \log \left(\text { Pen }_{25}\right)-T_{P i K}-120}
$$

where:

PI - penetration index, [-];

$\operatorname{Pen}_{25}$ - penetration of a binder at $25^{\circ} \mathrm{C},[\mathrm{mm} / 10]$;

$\mathrm{T}_{\mathrm{PiK}}-$ softening point of a binder, $\left[{ }^{\circ} \mathrm{C}\right]$. 
Temperature susceptibility of the binder can also be defined by means of SMI - Shear Modulus Index. This index is determined from the value of dynamic shear modulus obtained using Dynamic Shear Rheometer for a wide range of temperatures that occur during operation of road pavements (in this case from $82^{\circ} \mathrm{C}$ to $0^{\circ} \mathrm{C}$ ), much wider than for determination of the penetration index. It enables more accurate assessment of temperature susceptibility. SMI index is determined on the basis of Walther's formula [2]:

$$
S M I_{T_{2} / T_{1}}=\left|\frac{\log \log \left|G_{T_{1}}^{*}\right|-\log \log \left|G_{T_{2}}^{*}\right|}{\log \left(T_{1}+273,15\right)-\log \left(T_{2}+273,15\right)}\right|
$$

where:

SMI - Shear Modulus Index (describing the temperature susceptibility of the binder)

$\left|G_{T_{1}}^{*}\right|$ - dynamic shear modulus at $\mathrm{T}_{1},[\mathrm{~Pa}]$

$\left|G_{T_{2}}^{*}\right|$ - dynamic shear modulus at $\mathrm{T}_{2}$, [Pa]

$T_{1} ; T_{2}$ - initial and final temperature in DSR tests $\left(\mathrm{T}_{1}>\mathrm{T}_{2}\right),\left[{ }^{\circ} \mathrm{C}\right] ; \mathrm{T}_{1}=82^{\circ} \mathrm{C}$, $\mathrm{T}_{2}=0^{\circ} \mathrm{C}$ was assumed.

\section{Analysis of results}

\subsection{Penetration Index PI}

The results of penetration and softening point of the analyzed asphalt binders are presented in table 1, whereas table 2 includes values of asphalt binders penetration index. The tests results are presented as the arithmetic mean values and uncertainty interval determined at significance level $\alpha=0.05$ according to the methodology described in [22].

Addition of rubber granulate, both activated and inactivated, causes reduction of asphalt binder penetration. Activated rubber modified asphalt binder exhibits higher toughness as compared to inactivated rubber modified one. Penetration decrease is so big that there follows a shift of bitumen in classification taking into account penetration at $25^{\circ} \mathrm{C}$ - from $50 / 70$ to $35 / 50$. After RTFOT aging the asphalt binders modified with activated rubber revealed penetration decrease, whereas, for binders modified with inactivated rubber a decrease in penetration was reported. As regards RTFOT and PAV aging methods, it was observed that modification with rubber (activated and inactivated) caused an increase in binder penetration. However, changes in the value of penetration for asphalt binders subjected to the aging processes are significantly smaller than before aging.

The influence of granulated rubber is also observed in the case of softening point values. Addition of $15 \%$ of rubber to the bitumen increased the softening point, whereas, the highest increase was reported for inactivated rubber - by app. 19\% as compared to the reference bitumen (unaffected with the process of aging). The same dependency was found for asphalt binder affected by aging RTFOT and PAV (increase by app. 12\% as compared to the reference bitumen after the process of aging RTFOT and PAV). Softening point increase was also observed for asphalt binder exposed to aging RTFOT, however, the increase is higher than before and after aging RTFOT and PAV. It needs to be noted that, in this case, a bigger increase in the softening point was obtained after adding activated rubber to bitumen (softening point $14^{\circ} \mathrm{C}$ higher than for the reference bitumen after RTFOT).

Addition of granulated rubber (both activated and inactivated) has a positive impact on asphalt binder temperature susceptibility through increasing the value of penetration index for all observation levels - before and after aging RTFOT and RTFOT + PAV, as compared to the reference bitumen. The process of aging, both RTFOT and RTFOT+PAV caused an 
increase in the penetration index for all the analyzed kinds of asphalt binders - the reference one and activated and inactivated rubber modified ones. The highest values of penetration index were reported for the tested asphalt binders after RTFOT and PAV aging.

Table 1. Results of determination of penetration and softening point of the investigated asphalt binders

\begin{tabular}{|c|c|c|c|c|c|c|}
\hline \multirow[b]{2}{*}{ Asphalt binder } & \multicolumn{3}{|c|}{ Penetration at $25^{\circ} \mathrm{C}[\mathrm{mm} / 10]$} & \multicolumn{3}{|c|}{ Softening point $\left[{ }^{\circ} \mathrm{C}\right]$} \\
\hline & $\begin{array}{c}\text { Before } \\
\text { aging }\end{array}$ & $\begin{array}{c}\text { after } \\
\text { RTFOT }\end{array}$ & $\begin{array}{c}\text { after } \\
\text { RTFOT } \\
+ \text { PAV }\end{array}$ & $\begin{array}{c}\text { Before } \\
\text { aging }\end{array}$ & $\begin{array}{c}\text { after } \\
\text { RTFOT }\end{array}$ & $\begin{array}{c}\text { after } \\
\text { RTFOT } \\
+ \text { PAV }\end{array}$ \\
\hline $50 / 70$ & $\begin{array}{c}56,9 \pm \\
0,3\end{array}$ & $\begin{array}{c}36,6 \pm \\
0,5\end{array}$ & $\begin{array}{c}20,4 \pm \\
0,7\end{array}$ & $\begin{array}{c}49,3 \pm \\
0,2\end{array}$ & $\begin{array}{c}54,6 \pm \\
0,3\end{array}$ & $\begin{array}{c}63,4 \pm \\
0,5\end{array}$ \\
\hline $\begin{array}{c}50 / 70+15 \% \\
\text { ACTIVATED } \\
\text { RUBBER } \\
\end{array}$ & $\begin{array}{c}41,9 \pm \\
1,0\end{array}$ & $\begin{array}{c}35,8 \pm \\
0,7\end{array}$ & $\begin{array}{c}22,8 \pm \\
0,8\end{array}$ & $\begin{array}{c}55,9 \pm \\
0,5\end{array}$ & $\begin{array}{c}68,6 \pm \\
0,2\end{array}$ & $\begin{array}{c}68,6 \pm \\
0,4\end{array}$ \\
\hline $\begin{array}{c}50 / 70+15 \% \\
\text { INACTIVATED } \\
\text { RUBBER }\end{array}$ & $\begin{array}{c}46,6 \pm \\
0,6\end{array}$ & $\begin{array}{c}38,2 \pm \\
0,8\end{array}$ & $\begin{array}{c}25,1 \pm \\
0,5\end{array}$ & $\begin{array}{c}58,9 \pm \\
0,2\end{array}$ & $\begin{array}{c}62,6 \pm \\
0,3\end{array}$ & $\begin{array}{c}71,4 \pm \\
0,4\end{array}$ \\
\hline
\end{tabular}

The highest values of penetration index were reached for inactivated rubber modified asphalt binders - this effect was achieved for all observation levels. Before the process of aging, PI value for inactivated rubber modified asphalt binder increased by 1.72 , whereas, for activated rubber modified binder, the value increased by 0.84 , as compared to the reference one. After RTFOT aging the non-activated rubber modified asphalt binder reached PI value higher by 1.70 than the reference one after RTFOT aging (for activated rubber modified asphalt binder the value of PI was by 0.78 higher than for the reference one after RTFOT). After RTFOT and PAV aging PI value of reactive rubber modified asphalt binder increased by 1,69 , whereas for activated rubber modified one it increased by 1.06 in comparison with the reference bitumen after RTFOT and PAV aging.

Table 2. Values of the tested asphalt binder penetration index

\begin{tabular}{|c|c|c|c|}
\hline \multirow{2}{*}{ Asphalt binder } & \multicolumn{3}{|c|}{ Penetration index } \\
\cline { 2 - 4 } & Before aging & After RTFOT & $\begin{array}{c}\text { After } \\
\text { RTFOT }+ \text { PAV }\end{array}$ \\
\hline $50 / 70$ & $-1,08 \pm 0,04$ & $-0,82 \pm 0,04$ & $-0,25 \pm 0,07$ \\
\hline $\begin{array}{c}50 / 70+15 \% \text { ACITIVATED } \\
\text { RUBBER }\end{array}$ & $-0,24 \pm 0,09$ & $-0,04 \pm 0,04$ & $0,81 \pm 0,06$ \\
\hline $\begin{array}{c}50 / 70+15 \% \text { INACTIVATED } \\
\text { RUBBER }\end{array}$ & $0,64 \pm 0,03$ & $0,88 \pm 0,05$ & $1,44 \pm 0,05$ \\
\hline
\end{tabular}

\subsection{Shear Modulus Index SMI}

Figures 1-6 show the results of asphalt binders tests carried out for a wide range of temperatures (from $0^{\circ} \mathrm{C}$ to $82^{\circ} \mathrm{C}$ ) by the method of Dynamic Shear Rheometer (DSR). Figures 1-3 show diagrams of the dynamic shear modulus $\left|G^{*}\right|$ in relation to temperature, whereas, figures 4-6 depict diagrams of phase angle $\delta$ dependency, in relation to temperature. It can be observed, on the basis of the tests results, that the diagrams of dependence $\left|G^{*}\right|=f(T)$ and $\delta=f(T)$ show significant differences in the modified asphalt binders properties, as compared to bitumen without addition of rubber, and slight differences between properties of activated and inactivated rubber modified asphalt binders. The highest inclination of diagram $\left|G^{*}\right|=f(T)$ has been observed for the reference 50/70 
penetration grade bitumen, whereas, for rubber modified asphalt binders the inclination decreases. It confirms the conclusion that addition of rubber decreases temperature susceptibility of asphalt binders. Modification of bitumen with rubber has also a positive influence on the phase angle which has significantly decreased, especially in the range of high surface operation temperature (especially above $30^{\circ} \mathrm{C}$ ). It reflects improvement in elastic properties of asphalt binders through their modification with addition of granulated rubber.

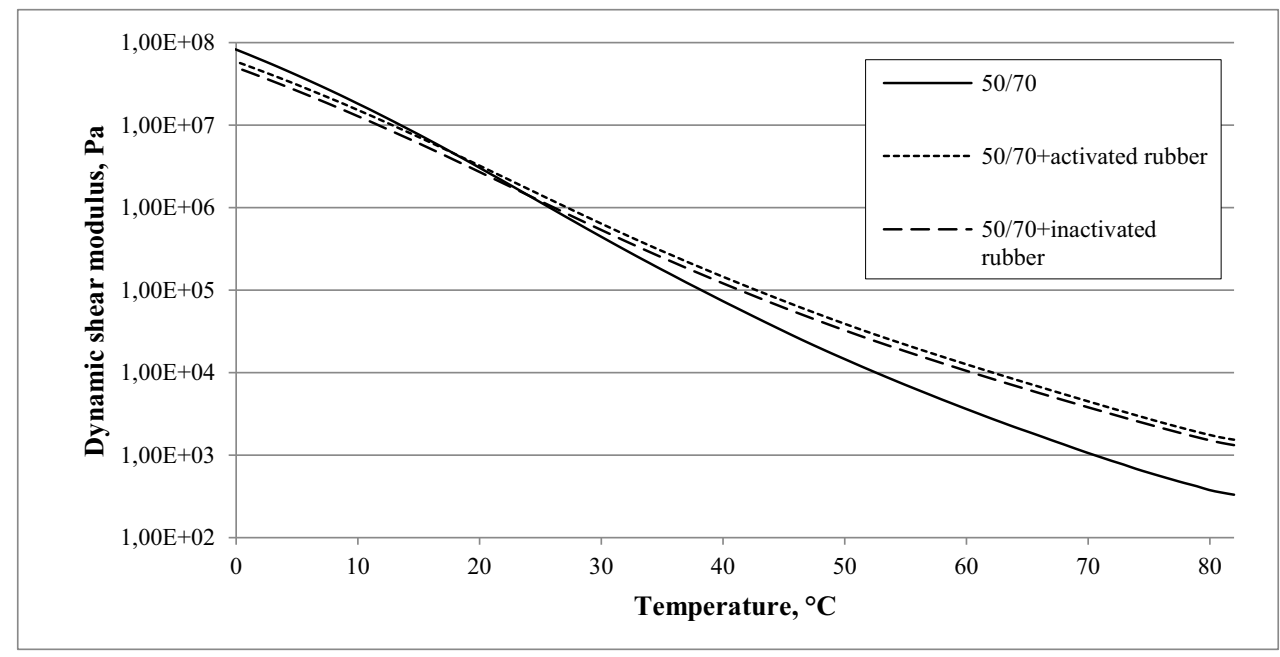

Fig. 1. Dynamic shear modulus in relation to temperature of unaged asphalt binders

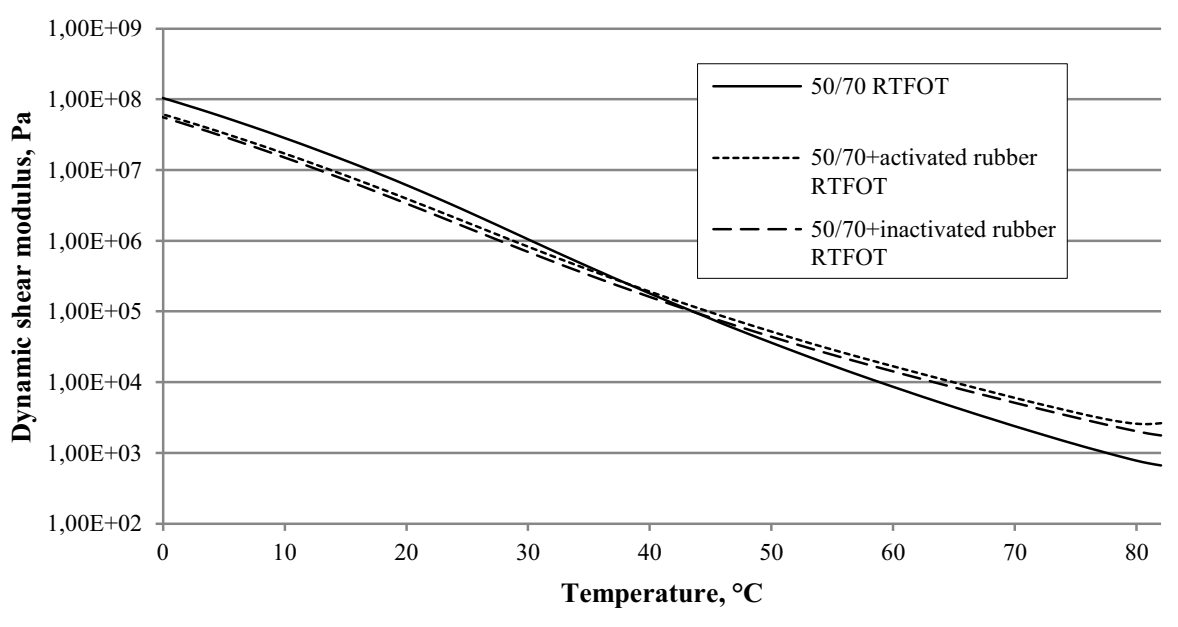

Fig. 2. Dynamic shear modulus in relation to temperature of the binders subjected to RTFOT aging 


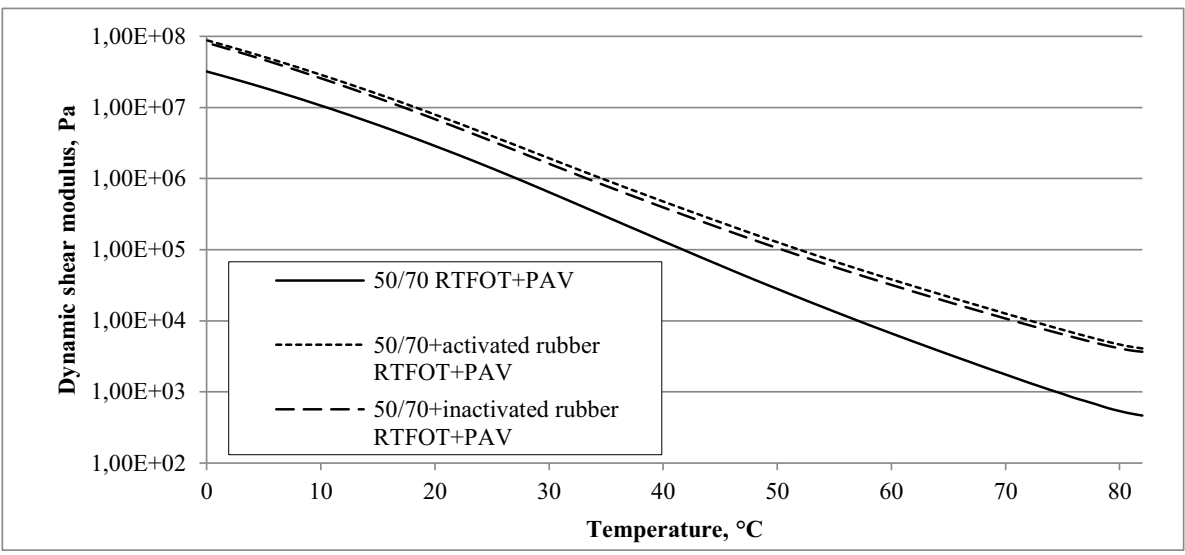

Fig. 3. Dynamic shear modulus in relation to temperature of the binders subjected to RTFOT and PAV aging

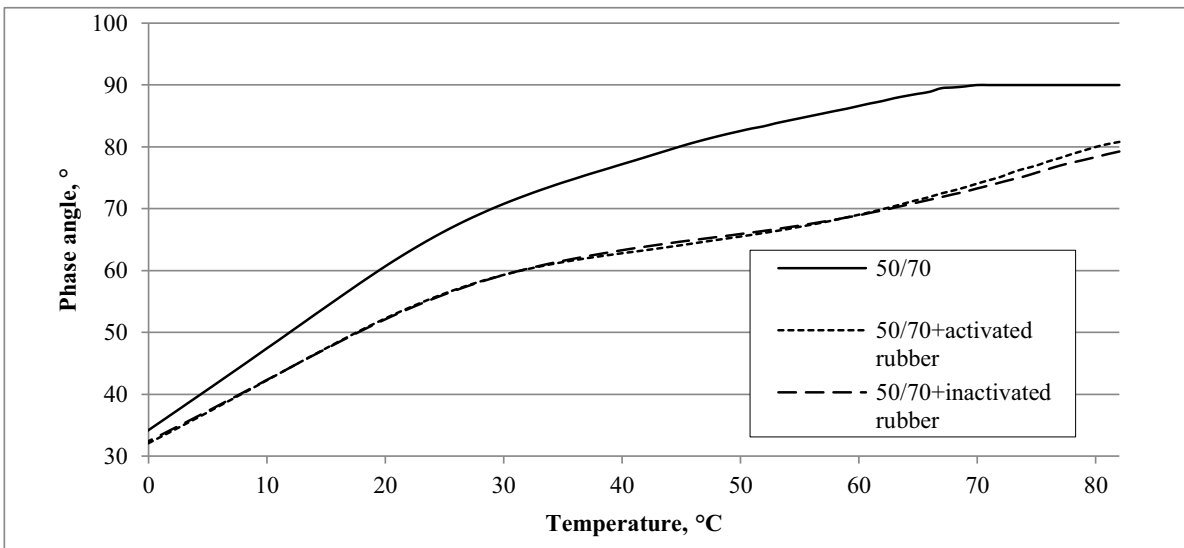

Fig. 4. Phase angle in relation to temperature of unaged asphalt binders

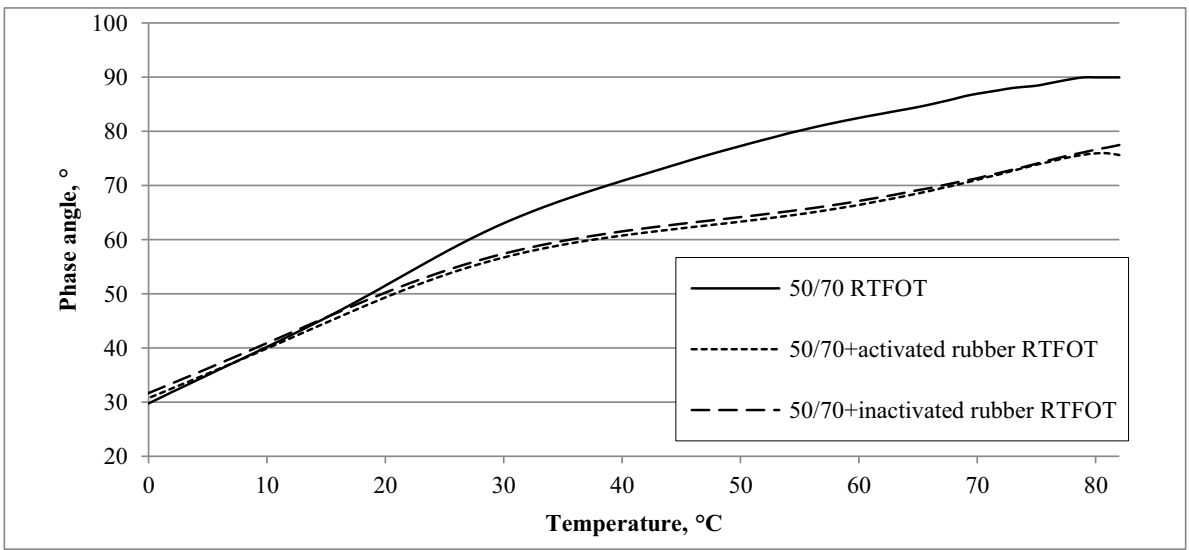

Fig. 5. Phase angle in relation to temperature of the binders subjected to RTFOT aging 


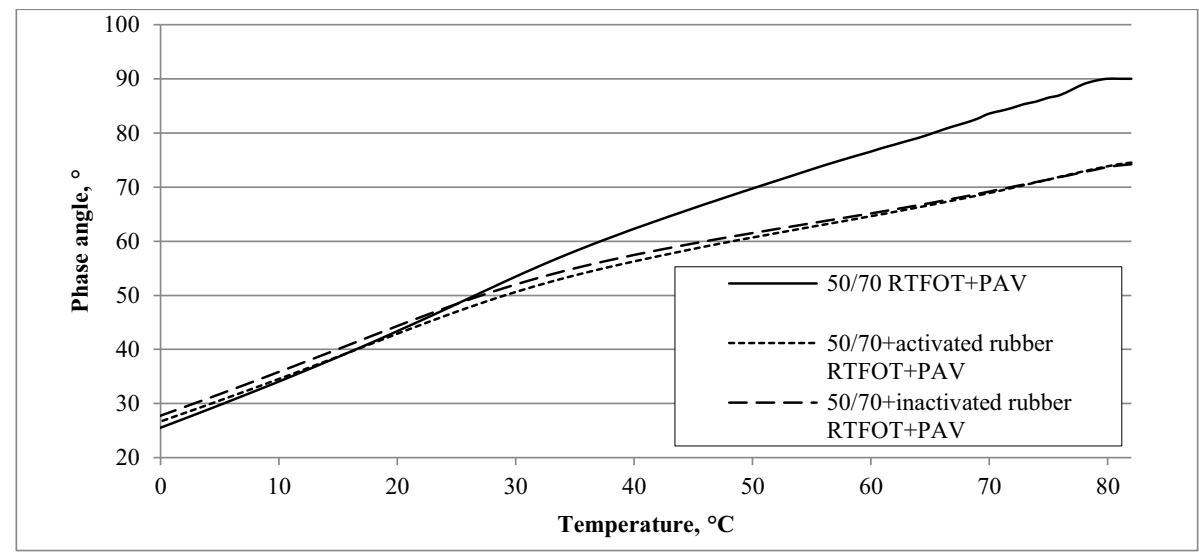

Fig. 6. Phase angle in relation to temperature of the binders subjected to RTFOT and PAV aging

Values of the shear modulus index SMI are presented in table 3. Addition of granulated rubber, both activated and inactivated, had an impact on reduction of SMI values, as compared to the reference bitumen, which proves its positive influence on asphalt binder temperature susceptibility. The lowest SMI values were observed for inactivated rubber modified asphalt binder both before and after short term and long term aging. As for activated rubber modified asphalt binder, lower SMI values before and after aging, were observed than for the reference bitumen which shows an improvement in the temperature susceptibility, slightly higher for inactivated rubber modified asphalt binder (4-8\% as compared to inactivated rubber modified asphalt binder).

On the basis of carried out tests it was observed that the process of aging has a positive influence on asphalt binder temperature susceptibility. The values of the SMI were found to be lower after aging than those before aging, for all the investigated binders. The lowest values of the shear modulus index (for the reference bitumen, as well as for activated and inactivated rubber modified asphalt binders) were reported for binders after RTFOT aging, though, SMI values after RTFOT and PAV aging are only slightly higher than after RTFOT aging (maximally $0.5 \%$ ).

Table 3. Values of shear modulus index of the investigated asphalt binders

\begin{tabular}{|c|c|c|c|}
\hline \multirow{2}{*}{ Asphalt binders } & \multicolumn{3}{|c|}{ SMI $0 / 82$} \\
\cline { 2 - 4 } & Before aging & After RTFOT & $\begin{array}{c}\text { After } \\
\text { RTFOT+PAV }\end{array}$ \\
\hline $50 / 70$ & 4,36 & 3,40 & 3,44 \\
\hline $\begin{array}{c}50 / 70+15 \% \text { ACTIVATED } \\
\text { RUBBER }\end{array}$ & 3,98 & 3,14 & 3,31 \\
\hline $\begin{array}{c}50 / 70+15 \% \text { INACTIVATED } \\
\text { RUBBER }\end{array}$ & 3,94 & 3,01 & 3,04 \\
\hline
\end{tabular}

\section{Conclusions}

The following conclusions can be formulated on the basis of the results of tests performed for activated and inactivated rubber modified asphalt binders.

a) Addition of granulated rubber (both activated and inactivated) has an influence on raising the softening point and reduction of 50/70 bitumen penetration, which causes a shift of the bitumen in classification concerning penetration determined at 
$25^{\circ} \mathrm{C}$ from type $50 / 70$ to $35 / 50$, which means that in result of rubber addition, bitumen has been stiffened. Similar changes in asphalt binder stiffness can be observed on the basis of analysis of the impact of short and long term aging, however, in this case the changes are smaller than for unaged bitumen.

b) Addition of rubber to 50/70 penetration grade bitumen causes an increase in the value of the analyzed binder penetration index, both before and after short and long time aging, whereas the lowest values of penetration index was found for the reference bitumen, whereas the highest for inactivated rubber modified asphalt binder. This proves that addition of rubber has a positive impact on a decrease in temperature susceptibility of the analyzed binder which is a desirable effect.

c) The process of aging improves temperature susceptibility of investigated asphalt binders through increasing penetration index PI (the highest values were obtained for asphalt binders after RTFOT and PAV aging) and shear modulus index SMI (the highest values were found for asphalt binders after RTFOT aging).

d) Addition of $15 \%$ of rubber (activated and inactivated) leads to reduction of the dynamic shear modulus value at low temperatures and its increase at high road pavement operational temperatures which confirms a positive impact of the rubber addition on asphalt binders temperature susceptibility.

e) Addition of activated and inactivated rubber contributes to a decrease in asphalt binder phase angle. This decrease is most visible for the high pavement operational temperatures (over $30^{\circ} \mathrm{C}$ ). On this basis, it can be concluded that addition of rubber causes improvement of the binder elastic properties.

\section{Literatura}

1. Radziszewski P., Nazarko J., Vilutiené T., Dębkowska K., Ejdys J., Gudanowska A., Halicka K., Kilon J., Kononiuk A., Kowalski K., Król J., Nazarko L., Sarnowski M.; Future trends in road pavement technologies development in the context of environmental protection; The Baltic Journal of Road and Bridge Engineering; 11(2):160-168, (2016).

2. Słowik M.; Thermorheological Properties Of Styrene-Butadiene-Styrene (SBS) Copolymer Modified Road Bitumen, Procedia Engineering 208: 145-150 (2017).

3. Lu X., Isacsson U.; Chemical and rheological evaluation of ageing properties of SBS polymer modified bitumens; Fuel 77(9): 961-972 (1998).

4. Navarro F.J., Partal P., Martinez-Boza F., Gallegos C.; Thermo-rheological behavior and storage stability of ground tire rubber-modified bitumens; Fuel 83(14): 20412019 (2004).

5. Sybilski D., Bańkowski W., Horodecka R., Wróbel A., Mirski K.; Method for modification of mineral-asphalt with addition of rubber „tecRoad”; Drogownictwo (6): 189-193 (2011).

6. Koba H., Skotnicki Ł., Szydło A.; Properties of rubber modified asphalt - practical application (viscosity, penetration decrease; Road building and maintenance (11): 378-382 (2010).

7. Kisgyörgy L., Toth C., Geiger A.; Elastic modulus of asphalt with chemically stabilized rubber bitumen, Elastic modulus of asphalt with chemically stabilized rubber bitumen; Gradevinar (68): 533-541 (2016).

8. Ramez Al.-Mansob, Amiruddin Bin Ismail, Nur Izzi Md. Yusoff, Mojtaba Shojaei Baghini; Rheological Characteristics of Epoxidized Natural Rubber Modified Bitumen; Mechanics and Materials Vols. 505-506: 174-179 (2014). 
9. Ibrahim M.R., Katman H.Y., Karim M.R., Kotling S., Mashaan N.S.; A review on the effect of crumb rubber addition to the rheology of crumb rubber modified bitumen; Materials Science and Engineering 3 (2013).

10. Radziszewski P., Sarnowski M., Król J., Kowalski K., Ruttmar I., Zborowski A.; Properties of rubber and mineral -rubber-modified asphalts, Warszawa (2017).

11. Radziszewski P., Kalabińska M., Piłat J.; Application of rubber modified asphalt in road building and maintenance; Drogownictwo (3): 73-77 (2001).

12. Koba H., Szydło A.; Influence of rubber modification on adhesion to rocks; Road building and maintenance (6): 198-201 (2010).

13. Radziszewski P., Plewa A.; Impact of rubber modified asphalt warming time on its viscoelastic properties; Drogownictwo (3): 86-49 (2003).

14. Pszczoła M., Jaczewski M., Szydłowski C., Dołżycki B., Judycki J.; Assessment of properties of low temperature mineral-asphalt mixtures with rubber and SBS modified asphalt properties; Conference on Modern Building Materials, Structures and Techniques; Wilno (2017).

15. Sun D., Li L.H.; Factors Affecting the Viscosity of Crumb Rubber-Modified Asphalt; Petroleum Science and Technology 28(15): 1555-1566 (2010).

16. Billiter T.C., Davison R.R., Glover C.J., Bullin J.A.; Physical properties of asphaltrubber binder; Petroleum Science and Technology 15(3-4): 205-236 (1997).

17. Silvrano A. Dantas Neto, Marcio M. Farias, Paulo A.A. Pereira, Jorge C. Pais; Influence of crumb rubber gradation on asphalt-rubber properties; Asphalt Rubber 2006: proceedings; 679-692 (2006).

18. Venudharan V., Krishna Prapoorna Biligiri; Effect of crumb rubber gradation on asphalt binder modification: rheological evaluation, optimization and selection; Materials and Structures 50(2): 129 (2017).

19. Najzarek Z., Wełnowski J., Novel mechanochemical technology for valorization of waste tire rubber, Conference InterNanoPoland, Katowice (2016).

20. Kok B.V., Yilmaz M., Sengoz B., Sengur A., Avci E.; Investigation of complex modulus of base and SBS modified bitumen with artificial neurol networks; Expert Systems with Applications 37; 7775-7780 (2010).

21. Styk S., Błażejowski K.; Technology of asphalt layers ; Wydawnictwa Komunikacji i Łączności; Warszawa (2014).

22. Słowik M.; Selected issues of viscoelasticity of modified road asphalts containing elastometer SBS; Dissertation series; no. 508; Wydawnictwo Politechniki Poznańskiej; Poznań (2013). 